\title{
El documento público ibérico. Algunas reflexiones sobre los bronces escritos
}

\author{
ARTURo OLIVER Folx ${ }^{*}$
}

En el abundante elenco de inscripciones ibéricas que se ha ido formando a lo largo de cuatro siglos de historiografía, podemos comprobar que el tipo de material usado para el soporte escriturario es muy variado, siendo los más frecuentes el de láminas de plomo, la piedra y como no la cerámica, esta última resulta ser la más numerosa y extendida de todas las clases de soporte sobre el que se han llevado a cabo los letreros ibéricos. En cambio, tan solo en un par de ocasiones encontramos que el bronce ha sido utilizado como soporte escriturario, localizándose los epigrafes en cuestión en dos yacimientos geograficamente cercanos entre si, es el de San Antonio en la castellonense población de Bechi y el del Castillo de Sagunto, distantes en línea recta tan solo 25 kilómetros. EI primer yacimiento corresponde a un pequeño asentamiento situado en la cumbre de una colina ubicada en medio de la planicie litoral del sur de Castellón, del cual tan solo tenemos escasos datos, pero presumiblemente pertenece a un momento tardío de la Cultura Ibérica. El segundo yacimiento es de sobras conocido debido a la importancia que tuvo en la II Guerra Púnica, aunque datos referentes a la fase ibérica se tienen pocos, tan solo en una ocasión se ha realizado una excavación dirigida a identificar este momento protohistórico (RovILLARD, 1979). Sin embargo, es abundante la bibliografía sobre la epigrafía ibérica localizada en el asentamiento, la cual se encuentra practicamente toda ella fuera de contexto debido a que pertenece a hallazgos casuales y de superficie. Al territorio de Sagunto, por lo menos en época romana, pertenecería el asentamiento de San Antonio de Bechi (Alföloy, 1977; Beltrán LloRIS, 1980, 359). Más difícil, en el estado actual de la investigación es conocer la relación

* Servicio de Investigaciones Arqueológicas y Prehistóricas de Castellón. 
entre ambos yacimientos en época ibérica. Presumiblemente el poblado de Bechi se situaría dentro del territorio saguntino, la Arse ibérica, aunque quizás el pequeño poblado dependería directamente de otro núcleo de población que a su vez sería jerarquicamnente subsidiario del centro principal, Sagunto. Así pues, San Antonio estaría dentro de la jerarquización del patrón de asentamiento de Sagunto, el cual se extendería desde su límite con el gran poblado de Edeta, la actual Liria, por la parte meridional (BERnABEu, et. al., 1987), hasta la zona del valle inferior del río Mijares, en lo que a su frontera septentrional se refiere, más difícil es conocer su territorio por poniente, pero más bien su influencia sería escasa, pues el interés de esta histórica población se centraría hacia los poblados de la costa.

\section{LOS EPIGRAFES IBÉRICOS SOBRE BRONCE}

Tal y como hemos indicado, en ambos yacimientos se han localizado los únicos epígrafes ibéricos sobre bronce. Los dos son hallazgos de furtivos, lo que impide conocer su contexto arqueológico, por lo tanto nos es completamente desconocida la datación y la funcionalidad de la zona en donde se encontraron dentro del yacimiento. También, la fragmentación en que se encuentran las piezas nos impide en gran manera valorar intrínsicamente estos interesantes documentos. No obstante, consideramos oportuno plantearnos algunas reflexiones en relación a las características materiales y formales de los epígrafes, pues su estudio se ha efectuado practicamente tan solo desde un punto de vista filológico con el fin de ampliar el vocabulario ibérico, hecho primordial para poder ir descifrando esta lengua (FLETCHER, 1968; 1969; 1984, Siles, 1985; VelazA, 1991).

La inscripción de Sagunto, que recibe el número XXVII (FLETCHER, 1984, 24; FLETCHER, SILGO, 1987), es un fragmento de una plancha de bronce, éste mide actualmente $23 \mathrm{~mm}$. de longitud por $25 \mathrm{~mm}$. de altura. Está escrita por una sola cara, en la cual los signos que ocupan dos líneas, emplean la mitad superior de la superficie, estamos pues, posiblemente ante la última línea del texto. La fragmentación del letrero que no ofrece ninguna palabra completa, nos impide aproximarnos a su contenido. La transcripción que de ella se da, y que se puede leer perfectamente es la siguiente:

$$
\begin{aligned}
& \text {...E R TO A... } \\
& \text {...CA U CO R... }
\end{aligned}
$$

J. Velaza ambos conjuntos de letras los considera como inicio de palabras (ertoa...; kaukor...) (VELAZA, 1991, 69,88). 
El bronce de San Antonio de Bechi, tal y como se ha indicado, tampoco está completo, mide el fragmento $780 \mathrm{~mm}$. de longitud por $850 \mathrm{~mm}$. de altura, presenta un porcentaje mayor de texto en relación al epigrafe saguntino. Al igual que el letrero anterior, tan solo ofrece una cara con los grafismos, que también están incisos, es una inscripción de seis líneas. Posee además esta lámina dos perforaciones, una en su extremo derecho inferior, tal y como se mira la pieza, y otra en el superior. Estas perforaciones al igual que vemos en otros bronces de diferentes culturas, como es el caso de la romana, servirían para sujetar el rótulo en un soporte mediante la aplicación de los correspondientes engarces, por lo cual es de suponer que estamos ante un letrero que se expondría al público. Las palabras que presenta corresponden practicamente en su totalidad a nombres propios, así tenemos el de Alorsin, Tibas y el conocido Sosin, ¿estamos pues, ante una relación pública de nombres?

La transcripción que de ella se da es la siguiente:

\section{(A) LORSIN ARICALERCA TIBAS ERTOIGIA $\angle A C U G I E C E N$ (S) OSINTIBA DUI}

Para J. Siles el cuarto signo de la palabra lacugiecen, aunque inseguro, sería S (SILES, 1985, 257). D. Fletcher quien publica inicialmente esta inscripción, presenta también dudas sobre la lectura de algunos grafismos, como leer $n o i$ al final de -dui.

Ante lo anteriormente expuesto, podemos indicar que estamos delante de dos epigrafes perfectamente identificables con la denominada escritura ibérica de levante, la cual es la más común y abundante en la zona en donde se encuentra, teniendo en cuenta además que es un área geográfica en la que son frecuentes los hallazgos epigráficos ibéricos.

\section{LA EPIGRAFIA IBÉRICA Y EL DOCUMENTO PÚBLICO ROMANO}

Estas dos muestras de epigrafía aquí comentadas nos llevan a plantear la existencia de un documento escrito ibérico de carácter público y emanado por una institución, la cual manda que se exponga publicamente, tal y como nos indican las perforaciones que el epigrafe de Bechí presenta en sus vértices. El tipo de material sobre el que se han realizado, también puede abundar sobre esta particularidad. El bronce en varias culturas ha ido ligado a la imagen del poder, ya que el material broncíneo ofrecía una connotación de prestigio que se veía incrementado en los letreros por el propio valor de la escritura. Esta característica de documento público contrasta con el resto de las inscripciones ibéricas que practicamente en su 
totalidad son de carácter privado. Es el caso de los grafitos de propiedad, las cartas comerciales, los escritos funerarios y religiosos y los documentos contables. Destaquemos, que este tipo de acción legal, como es la exposición pública de un documento, en la península ibérica y en lengua no latina, tan solo se había constatado en la zona celtibérica y debido como no, a la influencia romana, ello lo vemos en el bronce escrito con lengua celtiberica del Cabezo de las Minas de Botorrita (Beltrán Martínez, 1974). Estos documentos toman como ejemplo las tabulae publicae propias de la legislación romana, de las cuales en Hispania tenemos abundantes ejemplos; incluso encontramos su reglamentación en leyes municipales, como es el caso de la Lex irnitana escrita sobre una tabla de bronce encontrada en Molino Postero (Sevilla), la cual dedica un capítulo a este acto administrativo. La legislación romana indica que algunos documentos deben de exponerse en los edificios públicos y en los lugares más concurridos. Es el caso de las appennes, cuya función era la de volver a realizar un escrito perdido de un particular. El trámite consistía en la petición por el interesado de que se expidiera nuevamente un documento extraviado, el interesado lo solicitaba y se le daba una copia para él y otra se exponia en el mercado público durante tres días, siendo autentificado por el magistrado municipal (PAOLI, 1942, 32). El emperador Gordiano dictó una constitución para establecer los títulos perdidos (GIRY, 1894). Este acto administrativo derivará posteriormente al precepto regio del documento perdido. No obstante, consideramos que los bronces ibéricos deben estar más en la línea de la documentación pública que de la privada, pues de la primera como hemos indicado, tenemos abundantes ejemplos en Hispania. Así por ejemplo, públicas debían ser las listas de los candidatos a los cargos municipales, debiéndose colocar en lugares accesibles al público (de plano), tal y como indica la Lex Malacitana, o la Tabula illicitana. No olvidemos que el bronce de Bechi parece más bien una relación de nombres de persona. También públicas eran las condiciones de los contratos para arrendar los bienes públicos, por ello se realizaba una propositio que consistía en la publicación de un anuncio en un lugar en donde resultase fácil la lectura ( $u t$ d. p. r. l. p.). Este instrumento de publicidad tenía especial interés para los efectos de las garantias hipotecarias de las praedia que eran las garantias recibidas del conductor, es decir del arrendador (Ons, 1953, 328-329).

La presencia de unos documentos públicos como los aquí tratados nos está indicando una administración compleja ibérica, posiblemente ya dentro del ordenamiento municipal romano, con instituciones de carácter ejecutivo y legislativo. Al no tener el contenido completo de los textos ni poder traducirlos no sabemos, como si que sucede en el bronce latino de 
Botorrita (FATAS, 1981), si el documento expuesto está corroborado por la Administración romana por medio de un representante autorizado, o una institución indigena era suficiente y autónoma para emanar la documentación aquí tratada.

La administración ibérica debido a la influencia romana usará por primera vez la escritura como elemento de prestigio, debido al respeto que infunde la documentación escrita entre la gente. El principal uso de la escritura ha sido durante milenios el reforzar el control burocrático y el poder militar (STONE, 1969, 84). Este tipo de documentación administrativa nos plantea también la existencia de los archivos públicos ibéricos para guardar la documentación emanada por la autoridad sobre los cuales no tenemos ningún dato.

También de época tardía y por influencia romana encontramos los otros epígrafes públicos o por lo menos semipúblicos de la Cultura Ibérica, son las lápidas funerarias dirigidas en gran manera a los viandantes que pasan por los caminos junto a los cuales están las necrópolis (OLIVER, 1994), por lo que estos epígrafes adquieren el carácter de públicos, aunque en este caso, al igual que vemos en la epigrafía funeraria romana de la que la ibérica es deudora, la funcionalidad que se persigue es la de la exaltación personal, concretamente del difunto que se menciona en el epitafio (SUSINI, 1982). En ellos encontramos también la influencia romana en la parte formal, pero la tradición indigena está presente en la lengua y la escritura que se emplean.

\section{LENGUA Y DOCUMENTO PÚBLICO}

Aunque la parte formal de los documentos corresponde integramente a la administración romana que estaría implantada en las poblaciones de esta zona saguntina en el momento de la realización de los textos, vemos que la escritura no es la latina, sigue siendo una escritura indígena. Ello nos está indicando que hay una ruptura entre el grado de romanización de las instituciones y del estamento social de los gobernantes, y el pueblo, al cual hay que dirigirse en su propia lengua. El estamento político siguiendo el término empleado por A. Sherwin-White, se ha "autorromanizado" inmediatamente (SHERWIN-WHITE, 1973), hay un interés en la asimilación del régimen administrativo de la ciudad romana (MARiN, 1988, 153), y posiblemente más en el caso de Sagunto que a partir del tratado del Ebro mantiene relaciones con Roma dentro del ámbito de la fides o de la deditio. El latín es la lengua del poder central y de sus representantes locales (CAMPANELI, 1989,679), Roma no practicó nunca una política lingüística directa para la difusión del latín. 
Pero también debemos de considerar que la lengua indígena se sigue empleando en textos escritos en plena romanización, en época imperial, y se habla aun durante más tiempo (GARCiA, 1967; OLIVER, 1986). No obstante, tengamos en cuenta la similitud cronológica entre el bronce celtibérico de Botorrita, primera mitad del siglo I a. de J.C. (BELTRÁN, 1974) y el latino (FATAS, 1981), por lo que no sería de extrañar la existencia de un bilingüismo en un primer momento de la implantación de la administración municipal romana en Hispania, pero siempre dentro de una forma romanizada de la documentación. Este bilingüismo administrativo tiene su principal representación en las acuñaciones de la propia ciudad saguntino, con el nombre ibérico y latino de ArseSaguntum (VILLARONGA, 1967). También podría estar indicado por una lápida presumiblemente bilingüe (BELTRÁN 1980), aunque el diferente tipo de ejecución de los grafismos ibéricos de los latinos podría señalarnos cronologías diferenciadas. Este bilingüismo se puede comprobar también en otras zonas del Imperio Romano (CAMPANILE, 1989), tal y como vemos entre los griegos de Marsella. En Sagunto las inscripciones latinas se pueden datar a partir de la segunda mitad del siglo I a. de J.C. (BELTRÁn, 1980).

Al tratar estos textos se nos plantea la pregunta de por qué no aparece este sincretismo administrativo en otras zonas, como puede ser la indiketa o la turdetana, es debido tal vez a que pasaron directamente a la lengua latina como idioma administrativo, tal y como nos podría indicar en la Bética el Bronce de Lascuta datado en la temprana fecha del 189 a. de J.C., y nos recuerda también Estrabon $(3,2,15)$ al decir «los que viven a uno y otro lado del Betis se han cambiado totalmente al estilo romano, y ya no recuerdan su propia lengua». En el latín hispano se conservaron elementos arcaizantes del siglo II-I a. de J.C. Io que indica que en esta época ya estaba en algunas zonas, especialmente en las colonias y municipios el latín (DíAZ, 1960). Vemos pues, que la latinización es diferente según la zona geográfica, el estamento social y la lengua indígena, ya que como bien sabemos el griego, por ejemplo, perduró perfectamente, y el púnico sobrevive en Cerdeña hasta el siglo III.

Por otra parte, la exposición de un documento nos está indicando un grado de alfabetización del pueblo, ya que si se presentaba publicamente era para darlo a conocer, lo que hace suponer que algunos ciudadanos podían acceder facilmente a su lectura.

\section{ADMINISTRACIÓN Y ESCRITURA EN LA CULTURA IBÉRICA PLENA}

Los otros pueblos mediterráneos como es el caso de los fenicios y griegos, que durante la larga existencia de la Cultura lbérica estuvieron en 
contacto con los iberos, no influyeron en la administración inaígena debido a que sus contactos practicamente en su totalidad eran comerciales, por 10 tanto tan solo presentan influencias en la documentación comercial (Hoz, 1993; OLIVER, e.p.). Los griegos desde el siglo VII a. de J.C., es decir, anteriormente a su contacto con los ibéricos, presentan leyes escritas, y se exponen en público, citemos por ejemplo algunas tablas de bronce con agujeros para suspenderlas, como es el caso del decreto de Argos o el tratado entre Elei y Erei de Olimpia, ambos del siglo $V$ a. de J.C. (MustI, 1986). Frente a la política meramente comercial de griegos y fenicios en la península ibérica, Roma al incorporar el territorio a su administración unifica el acto administrativo tanto en su forma como en su contenido.

Todo ello nos lleva a preguntarnos el por qué durante cuatro siglos la administración ibérica no ha necesitado de la escritura, ¿estábamos ante una legislación basada en la tradición como nos puede indicar la cita de Estrabón sobre las leyes en verso de los turdetanos, que presumiblemente serian memorizadas y por tanto no necesitarian de la escritura? (ESTRABón, III, cap. II, párr. 6), o es que el tipo de gobierno personalizado no propicia este hecho, pues no requería participar al pueblo los actos de gobierno o legislativos. ¿O se usaría tal vez un soporte escriturario que no ha perdurado?. Probablemente esta participación del pueblo se introducirá al mundo indígena con el ordenamiento romano en las ciudades, ya que ello implica la aparición de las magistraturas ciudadanas electivas anualmente. Sin embargo, no queremos dejar pasar por alto en relación a esta problemática de la administración indígena, la mención que se hace en las fuentes escritas de la existencia de un senado en la población de Sagunto (LIVIO, 21, 12, 14), senado que es compatible también con un mando personalizado como puede ser un "praetor", y que no es necesario que se dé tan solo en casos excepcionales, como se deduce de las fuentes clásicas escritas cuando se refieren al nombramiento de un praetor para Sagunto durante la II Guerra Púnica. No obstante, el funcionamiento de esta asamblea o senado nos es completamente desconocida, por lo tanto no sabemos si habría un senado oligárquico o si existía un mínimo de participación del pueblo en el gobierno de la ciudad a través de él.

\section{LA PROBLEMÁTICA CRONOLÓGICA}

La cronología de la documentación aquí presentada ofrece la problemática mencionada más arriba y referida al tipo de hallazgo de las piezas, pues tal y como hemos indicado no provienen de excavaciones sistemáticas, por lo que su contexto cronoestratigráfico nos es completamente desconocido. 
Indudablemente debemos movernos en unas cronologías que deben de ir entre el 200 y el 50 a. de J.C.. Aunque las fuentes escritas nos hablan poco de la actividad administrativa, parece ser que después de la conquista hay una continuidad en cuanto al gobierno de las poblaciones, se nombra un praefectus que se superpone al ordenamiento político indígena de la ciudad, el cual seguirá posiblemente con el mismo tipo de gobierno que anteriormente. Indudablemente la fecha debe ser posterior a la II Guerra Púnica momento en que se incorporan las tierras orientales de la península ibérica a la República romana. Hacia el 120 a. de J.C., aparecen las primeras acuñaciones de Sagunto con los nombres de los magistrados en latín (GIL, 1966, 124; Villaronga, 1967, 107), es el caso de Marcus Acilius, nomen de una gens plebeya romana. Ello podría indicarnos un cambio en el carácter de la administración local hacia una mayor romanización de las instituciones, y como no a una propaganda de romanización de cara a la población, no olvidemos el fuerte poder de propaganda política que tienen las monedas (BALIL, 1964; GARZón, 1988). La existencia de un magistrado proveniente presumiblemente de Italia podría indicar el inicio de la aparición de la documentación pública en lengua latina o por lo menos en formato latino. No nos resistimos a señalar, que durante estas fechas iniciales del último cuarto del siglo II a. de J.C., se abandonan algunos poblados ibéricos según las cerámicas de barniz negro y sin haberse detectado en las excavaciones un motivo claro aparente, es el caso de la Moleta del Remei de Alcanar (Tarragona) (PALLARES, et al., 1985) y el Puig de la Misericordia de Vinaròs (Castellón) (OLIVER, 1994), y está reciente la fundación de la vecina población de Valencia. El momento final de las inscripciones indígenas en la zona saguntina, también lo podría señalar la elevación de la ciudad de Sagunto a la categoría de municipium civium romanorum, hecho que sucedería entre el año 56 y el 30/27 a. de J.C. (BeLtRán LlORIS, 1980, 386), momento a partir del cual tenemos constatados los epígrafes latinos, como uno relacionado con un decreto del ordo local referido a la reedificación de torres y murallas (BELTRÁN LLORIS, $1980,72)$. Ello nos indicaría ya una plena romanización de la administración en la que había sido hasta entonces civitas foederata, categoria que recibe durante la II Guerra Púnica o poco después de ella, lo que podría explicar la aparición por primera vez del documento público en un poblamiento ibérico. En el status de las civitates foederatae, cabe destacar «la conservación de una amplia autonomía interna que les permitía el uso de sus propias leyes (uti suilegibus), cuya jurisdicción recaia incluso sobre posibles ciudadanos romanos que vivieran en dichas ciudades" (MARIN, $1988,27)$, por lo tanto vemos que estamos ante un fuerte sincretismo político-administrativo, una estructura política indígena vigilada por un itálico, 
el cual introduciría algunos aspectos formales de la administración romana. El pleno ordenamiento municipal romano se encuentra perfectamente constatado en el bronce latino del Cabezo de las Minas de Botorrita fechado en el año 87 a. de J.C., el cual es el más antigua de los documentos jurídicos hispanos después del mencionado Bronce de Lascuta, ya que otras tablas de bronce se datan en el siglo I d. de J.C., incluso las que hacen referencia a promulgaciones anteriores, como la Ley municipal de Osuna, Lex Coloniae Genetivae lulius sive Ursonensis, dada por Antonio en el 44 a. de J.C. En la parte oriental del imperio el latín precisamente solo está presente como lengua del ejercito y de la administración de justicia (CAMPANELI, 1989, 686), lo que podría justificar la temprana presencia en los textos mencionados de Botorrita y Lascuta. Durante el inicio del sigo I existe una tendencia a legislar con el fin de unificar la administración municipal, siendo importantes en ello la Lex lulia del 90 a.C., y la Lex Plantia Papira de civitate sociis, dada en el año 89 a.C.

\section{CONSIDERACIONES FINALES}

Tal y como podemos comprobar el interés público de la escritura, es decir el permitir una lectura plural y de masas de un documento, el trasmitir un mensaje por vía visual, llega a la Cultura lbérica en época tardía y por influencia de Roma, es el caso de las lápidas sepulcrales o la documentación administrativa, así como los grafitos de los centros cultuales rupestres, estos tipos de letreros son los únicos que se realizan pensando que el lector será anónimo, o como mucho, sabiendo tan solo que el lector es el pueblo en general, concepto diferente a la documentación escrita ibérica que veiamos hasta ahora, ya sea comercial o religiosa que va dirigida a un destinatario concreto o a lo sumo a una divinidad. Este interés en hacer público los documentos administrativos podria indicarnos también un cambio en la administración pública, en el gobierno, el pueblo si no participa por lo menos debe de ser sabedor, hecho que puede contrastar con planteamientos políticos de jefaturas o aristocráticos muy cerrados, como los que podrian haber en época ibérica antigua y plena, los cuales siempre han rehuido de las leyes escritas y complejas, frente a la legislación democrática más precisa y compleja. También es verdad que en régimenes aristocráticos griegos (eunomia) se dan igualmente casos de escritos públicos, pero la escritura tal y como opina D. Musti, aunque no la creó la democracia si que la promocionó (MUSTl, 1986,22). Esta "democratización» en la península ibérica viene indudablemente a través de la República romana a la cual se incorpora la región ibérica durante el lbérico 
tardio. Es un hecho más que contrasta con la influencia de la democracia griega, ya que el sistema político ateniense no influyó en la administración ibérica. Indudablemente porque los intereses con los griegos tal y como hemos indicado eran de comercio y no de gobierno, y para el comerciante griego era más fácil controlar el mercado a través de una persona que sería el aristócrata o el regulo de la zona que dominará el poder económico y por tanto el político.

La falta de conocimiento que tenemos sobre la forma en que influenció la administración romana sobre la indígena en los primeros momentos de la romanización, así como la efectividad que ejerció el gobierno romano, debe ser una línea de investigación para futuros trabajos sobre la romanización.

Los interrogantes planteados en las líneas precedentes son más que las soluciones que hemos podido aportar al tema, pues la documentación que tenemos actualmente es a todas luces escasa, pero creemos que cuando ya se ha empezado a ver los diferentes estamentos sociales y de gobierno de la Cultura lbérica, debemos también comenzar a plantearnos cómo se llevó a cabo la administración de las diferentes ciudades ibéricas. Indudablemente dos fragmentos de inscripción constituyen una escasa base para plantear una línea de trabajo, pero son un motivo de reflexión que puede ayudarnos a iniciar el camino.

\section{BIBLIOGRAFIA}

Alföldy, G., (1977): Res publica leserensis (Forcall, Castellón). Serie de Trabajos Varios, 55. Valencia.

BALIL., A., (1964): Política y propagandas de las acuñaciones severianas. Estudios de numismática romana, págs. 5-24. Barcelona.

Bernabeu, J., Bonet, H., Mata, C., (1987): Hipótesis sobre la organización del territorio edetano en época ibérica plena: el ejemplo del territorio de Edeta/Lliria. /béros. Actas de las I Jornadas sobre el mundo ibérico (Jaén, 1985), págs.137-156. Jaén.

Beltrán LloRIS, F.J., (1980): Epigrafía latina de Saguntum y su territorium. Serie de Trabajos Varios, 67. Valencia.

Beltrán Martinez, A., (1973): Avance al estudio del bronce ibérico de Botorrita (Zaragoza). Actas del XII Congreso Nacional de Arqueologia (Jaén, 1971), págs. 451-454. Zaragoza.

BELTRÁN MARTíneZ, A., (1974): La inscripción ibérica sobre bronce de Botorrita (Zaragoza). Homenaje a Don Pio Beltrán, anejo al Archivo Español de Arqueología, págs. 73-85. Madrid.

Campanile, E., (1989): Le lingue dell'impero. Storia di Roma, vol. IV. Roma.

Diaz Diaz, M., (1960): Rasgos lingüisticos. Enciclopedia lingüística Hispánica, T. l., págs. 153 y ss. Madrid.

Fatas, G., (1977-1978): El nuevo bronce de Contrebia. Pyrenae, 13-14, págs. $193-209$. Barcelona.

FATAS, G., (1981): El bronce de Contrebia Belaisca. Cuadernos de Trabajos de la Escuela Española de Historia y Arqueología en Roma, 15, págs. 57-66. Roma.

FletCheR VALLS, D., (1968): Un bronce escrito del poblado ibérico de San Antonio (Bechi, Castellón): Zephyrus, XVIII, págs. 79-83. Salamanca.

Fletcher Valls, D., (1969): Un bronce escrito del poblado de San Antonio (Bechi, Castellón). Arse $X$, págs, 6-10. Sagunto. 
FLeTCHer VALLS, D., (1970): Neue iberische Inschriften aus der Provinz Castellón de la Plana. Die Sprache, XVI, 2, págs. 149 y ss.

Fletcher Valls, D., Mesado Oliver, N., (1968): Nuevas inscripciones ibéricas de la provincia de Castellón. Boletín de la Sociedad Castellonense de Cultura, XLIV, págs. 137 y ss. Castellón.

FLETCHER VALLS, D., (1984): Dos pequeños textos ibéricos procedentes de Sagunto. Arse, 19 , págs. 23-26. Sagunto.

FLETCHER VALLS, D., SILGo GaUCHE, L., (1987): Repertorio de inscripciones ibéricas procedentes de Sagunto (Valencia). Arse, 22, págs. 659-669. Sagunto.

Garcia y Bellido, A., (1967): La latinización de Hispania. Archivo Español de Arqueología, 40, págs. 3-29. Madrid.

GARZÓN BlASCO, J.A., (1988): La propaganda imperial en las monedas de Hércules, “Hercules gaditanus", Minerca y "Minerva gaditana" emitidas desde trajano a Antonino Pio. Baética, 11, págs. 257-265. Malaga.

GIL FARRES, O., (1966): Moneda hispánica en la Edad Antigua. Madrid.

GIRY, A., (1894): Manuel de diplomatique. Paris. Reedición de Burt Franklin. New York.

Hoz, J., (1993): Las sociedades paleohispánicas del área no indoeuropea y la escritura. Archivo Español de Arqueología, 66, págs. 3-30. Madrid.

MARIN DIAZ, M.A., (1988): Emigración, colonización y municipalización en la Hispania republicana. Granada.

MUSTI, D.,(1986): Democrazia e scritura. Scrittura e civiltà, 10, págs. 21-48. Roma.

OLIVER Folx, A., (1986): La epigrafía iberica y romana como elemento sintomático de influencia cultural. Aportaciones al proceso escriturario en la Edad Antigua. Boletín de la Sociedad Castellonense de Cultura, LXI, págs. 33-48. Castellón.

OLIVER Folx, A., (1994): El poblado ibérico del Puig de la Misericordia de Vinaròs. Vinaròs.

OLIVER FOIX, A., (1994). Aproximación a la problemática de las estelas epigráficas funerarias ibéricas no decoradas. $V$ Congreso de Estelas Funerarias, Vol. I, págs. 107-116. Soria.

OLIVER Folx, A., (e.p.). Los grafitos prelatinos de la Peninsula Ibérica: una escritura no marginal. Actas del II Seminari Internacional d'Estudis sobre la Cultura Escrita. Valencia.

ORSA, A. d', (1953): Epigrafía juridica de la España romana. Madrid.

Pallares, R., Gracia, F., Munilla, G., (1985): Cerámicas áticas de barniz negro del poblado ibérico de la Moleta del Remei (Alcanar, Montsià). Empuries, 47, págs. 120-129. Barcelona

PAOLI, C., (1949): Diplomatica. Nuova edizione aggiornata da G.C. Bascapè. Manuali di filologia e storia. Serie I, volume I. Florencia. Reedición de 1969.

Petruccl, A., (1985): Potere, spazi urbani, scritture esposte: proposte ed esempi. Actas de la mesa redonda sobre Culture et idéologie dans la genèse de l'état moderne (Roma, 1984), págs. 85-97. Roma.

RouILLARD, P.. (1979): Investigación sobre la muralla ibérica de Sagunto. Serie de Trabajos Varios, 62. Valencia.

SILES, J., (1985): Léxico de inscripciones ibéricas. Madrid.

StONe, L., (1969): Literacy and Education in England. 1640-1900. Past and Present, 42. Londres.

SUSINI, G.C., (1982): Epigrafia romana. Roma.

VELAZA, J., (1991): Léxico de inscripciones ibéricas (1976-1989). Aurea Saecula, 4. Barcelona. ViLLARONGA, L., (1967): Las monedas de Arse-Saguntum. Barcelona. 